\title{
Dairy cheese consumption ameliorates single-meal sodium-induced cutaneous microvascular dysfunction by reducing ascorbate-sensitive oxidants in healthy older adults
}

\author{
Anna E. Stanhewicz ${ }^{1 *}$, Billie K. Alba ${ }^{2}$, W. Larry Kenney ${ }^{1,2}$ and Lacy M. Alexander ${ }^{1,2}$ \\ ${ }^{1}$ Center for Healthy Aging, Pennsylvania State University, University Park, PA 16802, USA \\ ${ }^{2}$ Department of Kinesiology, Pennsylvania State University, University Park, PA 16802, USA \\ (Submitted 9 March 2016 - Final revision received 31 May 2016 - Accepted 31 May 2016 - First published online 1 July 2016)
}

\section{Abstract}

Chronic dairy product intake is associated with improved cardiovascular outcomes, whereas high dietary Na impairs endothelial function through increased oxidative stress and reduced nitric oxide (NO) bioavailability. The purpose of this study was to compare the effect of acute cheese consumption with consumption of Na from non-dairy sources on microvascular function. We hypothesised that dairy cheese ingestion would augment NO-dependent vasodilation compared with Na from non-dairy sources. On five visits, fourteen subjects (61 (sEM 2 ) years, eight male/six female) consumed either $85 \mathrm{~g}$ dairy cheese ( $560 \mathrm{mg} \mathrm{Na}$ ), $85 \mathrm{~g}$ soya cheese ( $560 \mathrm{mg} \mathrm{Na}$ ), $65 \mathrm{~g}$ pretzels ( $560 \mathrm{mg}$ Na), $170 \mathrm{~g}$ dairy cheese $(1120 \mathrm{mg} \mathrm{Na})$ or $130 \mathrm{~g}$ pretzels ( $1120 \mathrm{mg} \mathrm{Na}$ ). Two intradermal microdialysis fibres were inserted in the ventral forearm for delivery of lactated Ringer's solution or $10 \mathrm{~mm}$-ascorbate (antioxidant) during local skin heating (approximately 50 min). Erythrocyte flux was measured continuously by laser-Doppler flowmetry (LDF), and cutaneous vascular conductance (CVC $=\mathrm{LDF} / \mathrm{mean}$ arterial pressure) was normalised as $\% \mathrm{CVC}_{\max }$ (28 mm-sodium nitroprusside). Following a plateau in CVC, $15 \mathrm{~mm}-N^{G}$-nitro-L-arginine-methyl-ester was perfused to quantify NO-dependent vasodilation (approximately $45 \mathrm{~min}$ ). NO-dependent vasodilation was greater following consumption of dairy products (560 mg Na 57 (SEM 3)\%) (1120 mg Na 55 (SEM 5)\%) compared with soya (560 mg Na 42 (sEM 3) \%; $P=0.002$ ) or pretzels (560 mg Na 43 (sEM 4) \%; $P=0.004$ ) (1120 mg Na 46 (sEm 3) \%; $P=0.04$ ). Ascorbate augmented NO-dependent vasodilation following intake of soya (control: 42 (SEM 3) $v$. ascorbate: 54 (SEM 3) \%; $P=0.01$ ) or pretzels (560 mg Na; control: 43 (sEM 4) $v$. ascorbate: 56 (SEM 3) \%; $P=0.006$ ) (1120 mg Na; control: 46 ( $\operatorname{sem} 5) v$. ascorbate: 56 (sem 3) \%; $P=0.02$ ), but not dairy products. Na ingestion via dairy products was associated with greater NO-dependent vasodilation compared with non-dairy products, a difference that was ameliorated with ascorbate perfusion. The antioxidant properties of dairy proteins may protect against Na-induced reductions in NO-dependent dilation.

\section{Key words: Dairy products: Cheese: Sodium: Nitric oxide: Vascular health}

CVD is the leading cause of mortality in developed nations, with $40 \%$ of all deaths in the USA attributable to CVD. The annual healthcare burden of treatment and management of CVD is $>\$ 656$ billion and is projected to increase as the population ages $^{(1)}$. As such, identification of modifiable risk factors and non-pharmacological interventions are important for CVD prevention. Increasing dairy product intake is an emerging lifestyle factor that is associated with a decreased CVD risk ${ }^{(2,3)}$. Long-term dairy product consumption is associated with lower blood pressure in healthy, aged individuals ${ }^{(4)}$, but its cardioprotective activities are mediated independent of its blood pressure-lowering effect ${ }^{(5-14)}$. A putative mechanism through which dairy product consumption may benefit vascular function is the antioxidant properties of dairy peptides. Administration of dairy peptides in animal models reduces markers of inflammation and attenuates measures of oxidative stress, including total antioxidant capacity ${ }^{(9,12,13)}$, suggesting that these mechanisms may decrease lifetime risk of cardiovascular morbidity and mortality.

A high dietary $\mathrm{Na}$ intake is independently associated with elevations in arterial blood pressure ${ }^{(15)}$ as well as increased cardiovascular morbidity and mortality ${ }^{(16)}$. Animal studies of the vascular effects of high dietary $\mathrm{Na}$ implicate endothelium-derived oxidative stress, particularly the production of superoxides, in reduced nitric oxide (NO) bioavailability and endothelial dysfunction $^{(17-21)}$. Similarly, human studies demonstrate that $\mathrm{Na}$ restriction $(\leq 1.5 \mathrm{~g} / \mathrm{d})$ reverses age-associated endothelial dysfunction by increasing NO-dependent vasodilation ${ }^{(22)}$. Similarly, non-invasive measures of conduit artery endothelial function show that low dietary $\mathrm{Na}$ intake is associated with enhanced flow-mediated vasodilation in middle-aged and older adults $^{(23)}$. In contrast to Na restriction, even short-term increases in dietary $\mathrm{Na}(7 \mathrm{~d})$ impair flow-mediated vasodilation in conduit arteries of otherwise healthy young adults ${ }^{(24-26)}$, and even a

Abbreviations: CVC, cutaneous vascular conductance; eNOS, endothelial nitric oxide synthase; NO, nitric oxide.

* Corresponding author: A. E. Stanhewicz, fax +814 865 4602, email axs1056@psu.edu 
single high-salt meal can significantly suppress brachial artery flow-mediated dilation within $30 \mathrm{~min}$ in healthy young adults ${ }^{(27)}$.

The human cutaneous circulation is an accessible vascular bed for examining mechanisms of microvascular dysfunction in vivo ${ }^{(28)}$. There is a significant relationship between microvascular dysfunction measured in the skin and that measured invasively in the coronary and renal circulations, and interventioninduced improvements in vascular function are detectible in the cutaneous circulation before improvements in clinical outcomes $^{(28-30)}$. Importantly, dietary Na-induced impairments in endothelial function are detectable in the cutaneous microvasculature of otherwise healthy adults, independent of changes in blood pressure or blood chemistry ${ }^{(25,31,32)}$. These mechanistic in vivo human studies further demonstrate that even short-term (7d) increases in dietary $\mathrm{Na}$ impair endothelial function and reduce $\mathrm{NO}$ bioavailability via an increase in oxidative stress $^{(23,25,31)}$

Increased consumption of dairy products in the form of natural cheese may inadvertently increase dietary $\mathrm{Na}$ intake. Consequently, increasing dairy product consumption, particularly in the form of cheese, may paradoxically hinder adherence to dietary Na recommendations, while still mitigating CVD risk. It is currently unknown whether vasoprotective activities of dairy products, provided as natural cheeses, protect against Na-induced impairments in the vasculature. Therefore, we sought to examine the protective role of macronutrients in natural dairy cheese against acute dietary Na-induced microvascular dysfunction. We hypothesised that acute natural dairy cheese ingestion would improve NO-dependent vasodilation compared with an equal dietary $\mathrm{Na}$ intake from non-dairy sources. Further, we hypothesised that this effect would be mediated by a reduction in ascorbate-sensitive oxidants.

\section{Methods}

\section{Subjects}

All protocols were approved by the Institutional Review Board at The Pennsylvania State University and complied with the guidelines in the Declaration of Helsinki. All participants voluntarily provided written and verbal consent before the experiment. In all, fourteen subjects (61 (SEM 2) years; eight men, six women) participated in the study. Before participation, subjects underwent a medical screening that included a twelvelead electrocardiogram, fasting blood chemistry and physical examination. Subjects also completed a 24-h ambulatory blood pressure monitoring while enrolled in the study. Inclusion criteria required a daily dairy product intake of less than two servings. Daily dairy product intake was assessed using a modified FFQ specific to dairy product consumption. Subjects had a $2-d$ wash-in period where they did not consume any dairy products. Experimental visits were separated by at least $3 \mathrm{~d}$, to ensure the $2 \mathrm{~d}$, low-dairy product wash-in before each visit. There were no recommendations regarding $\mathrm{Na}$ intake during the wash-in period. Subjects abstained from alcoholic and caffeinated beverages for $12 \mathrm{~h}$, vigorous physical activity for $24 \mathrm{~h}$ and food for $8 \mathrm{~h}$ before each experiment. All subjects were non-smokers, non-diabetic, non-obese $\left(\mathrm{BMI}<30 \mathrm{~kg} / \mathrm{m}^{2}\right)$ and
Table 1. Human subject characteristics (Mean values with their standard errors)

\begin{tabular}{lcll}
\hline & Mean & & SEM \\
\hline Sex (M, F) & & 8,6 & \\
Age (years) & 61 & & 2 \\
BMI (kg/m $\left.{ }^{2}\right)$ & 25.9 & 0.4 \\
SBP (mmHg) & 127 & 2 \\
DBP (mmHg) & 77 & 1 \\
Total cholesterol (mmol/l) & 5.2 & 0.2 \\
HDL (mmol/l) & 1.5 & 0.1 \\
LDL (mmol/l) & 3.3 & 0.2 \\
HbA1c (\%) & 5.7 & 0.1 \\
\hline
\end{tabular}

M, male; F, female; SBP, systolic blood pressure; DBP, diastolic blood pressure; $\mathrm{HbA1c}$, glycated $\mathrm{Hb}$.

were not taking prescription medications that may alter vascular function (e.g. statins, antidepressants, antihypertensives, dietary supplements, aspirin, etc.). Women taking any form of hormone-replacement therapy were excluded from the study. Subject characteristics are presented in Table 1.

\section{Experimental protocol}

Fig. 1 presents a schematic representation of the experimental protocol. On five separate visits, subjects arrived at the laboratory following an overnight $(\geq 8 \mathrm{~h})$ fast. Each experimental visit spanned approximately $4 \mathrm{~h}$. For the local delivery of pharmacological agents, two intradermal microdialysis fibres (10-mm, 20-kDa cut-off membrane, MD 2000; Bioanalytical Systems) were placed into the dermal layer of the ventral left forearm $^{(33)}$. Pharmacological agents were mixed just before use, dissolved in lactated Ringer's solution, sterilised using syringe microfiltres (Acrodisc; Pall) and wrapped in foil to prevent degradation due to light exposure. Microdialysis sites were randomly assigned to receive either $10 \mathrm{~mm}$-ascorbic acid (Sigma) for local delivery of the non-specific antioxidant ${ }^{(31,34)}$ or lactated Ringer's solution to serve as control. Site-specific pharmacological solutions were perfused through the microdialysis fibres at a rate of $2 \mu \mathrm{l} / \mathrm{min}^{(33,35)}$ (Bee Hive controller and Baby Bee microinfusion pumps; Bioanalytical Systems).

Following microdialysis fibre placement, subjects were instrumented with an intravenous catheter for blood collection. A fasted sample was collected before dietary treatment administration. Blood samples were then collected every $30 \mathrm{~min}$ after treatment until completion of the study. Whole blood samples were collected in EDTA-treated tubes containing o-phenanthroline, $p$-hydroxymercuribenzoic acid and pepstatin (Wake Forest University). Whole blood samples were centrifuged, and plasma samples were frozen and stored at $-80^{\circ} \mathrm{C}$ until future use. Plasma $\mathrm{Na}$ was measured at baseline and at $90 \mathrm{~min}$ after ingestion using an electrolyte analyzer (ProLyte; Diamond Diagnostics). Plasma angiotensin II concentrations were measured at baseline and at 90 min after ingestion using a commercially available ELISA kit (Abcam) according to the manufacturer's instructions. Samples were analysed in duplicate with an average CV $<10 \%$.

Subjects consumed either $85 \mathrm{~g}$ Cheddar dairy cheese $(560 \mathrm{mg} \mathrm{Na}), 85 \mathrm{~g}$ soya cheese $(560 \mathrm{mg} \mathrm{Na}), 65 \mathrm{~g}$ pretzels 


\begin{tabular}{|c|c|c|c|c|}
\hline \multirow[b]{2}{*}{$\begin{array}{c}\text { Hyperemia } \\
\text { (approximately } 60 \mathrm{~min} \text { ) }\end{array}$} & \multirow[b]{2}{*}{ Baseline $33^{\circ} \mathrm{C}$} & \multicolumn{2}{|c|}{ Local heating } & \multirow[b]{2}{*}{ Maximum VD } \\
\hline & & Heat to $42^{\circ} \mathrm{C}$ & $42^{\circ} \mathrm{C}$ & \\
\hline $\begin{array}{l}\text { 1. MD fibre placement } \\
\text { 2. Fasted blood draw }\end{array}$ & \multicolumn{2}{|c|}{ Control: lactated Ringer's } & 15mm L-NAME & $\mathrm{SNP}, 43^{\circ} \mathrm{C}$ \\
\hline $\begin{array}{l}\text { 3. Ingest treatment } \\
\text { 4. Instrumentation }\end{array}$ & \multicolumn{2}{|c|}{ Antioxidant: ascorbate } & 15mM L-NAME & $\mathrm{SNP}, 43^{\circ} \mathrm{C}$ \\
\hline
\end{tabular}

Fig. 1. Schematic representation of the protocol. Subjects entered the laboratory after fasting, had two intradermal microdialysis fibres placed, a fasted blood draw and then ingested the treatment diet. Following the resolution of hyperaemia, subjects were instrumented and skin blood flow data were collected at baseline, throughout local heating and during maximal vasodilation. The entire protocol lasted approximately $4 \mathrm{~h}$. Each arrow represents a microdialysis site. L-NAME, $N^{G}$-nitro-L-arginine; SNP, sodium nitroprusside; VD, vasodilation.

Table 2. Sodium, energy and macronutrient contents of dietary treatments

\begin{tabular}{lrcrrr}
\hline & $85 \mathrm{~g}$ Cheddar cheese & $85 \mathrm{~g}$ soya cheese & $65 \mathrm{~g}$ pretzel & $170 \mathrm{~g}$ Cheddar cheese & $130 \mathrm{~g}$ pretzel \\
\hline $\mathrm{Na}(\mathrm{mg})$ & 560 & 560 & 560 & 1120 & 1120 \\
Energy content $(\mathrm{kJ})$ & 1506 & 879 & 1067 & 3012 & 2130 \\
Energy content $(\mathrm{kcal})$ & 360 & 210 & 255 & 720 & 509 \\
Fat $(\mathrm{g})$ & 28 & 6 & 0 & 56 & 0 \\
Carbohydrate $(\mathrm{g})$ & 0 & 3 & 56 & 40 & 112 \\
Protein $(\mathrm{g})$ & 20 & & & & \\
\hline
\end{tabular}

( $560 \mathrm{mg} \mathrm{Na}), 170 \mathrm{~g}$ dairy cheese (1120 mg Na) or $130 \mathrm{~g}$ pretzels $(1120 \mathrm{mg} \mathrm{Na})$ in a randomised order $30 \mathrm{~min}$ after microdialysis fibres were placed. The treatment order was randomly assigned for each subject using a random number generator and was administered by the investigators; one subject did not consume soya cheese because of palatability issues. Our initial study design included a 170-g soya cheese treatment (1120 mg Na); however, several subjects refused this treatment because of palatability and we excluded it from further testing. The energy, macronutrient and $\mathrm{Na}$ contents of each dietary treatment are displayed in Table 2. The 30-min time point for consumption was chosen such that the local heating plateau for our endothelial nitric oxide synthase (eNOS)-dependent vascular stimulus ${ }^{(33)}$ would occur 60-90 min after treatment, corresponding with the time period after milk peptide ingestion when peak intestinal concentrations of bioactive peptides are recovered ${ }^{(36)}$.

We allowed 60-90 min for hyperaemia associated with fibre placement to resolve before baseline data were collected, followed by a standard local heating protocol to induce eNOS-dependent vasodilation as previously described ${ }^{(33,37)}$. After approximately 30-40 min of local heating, when skin blood flow reached an established plateau, $15 \mathrm{~mm}-N^{G}$-nitro-L-arginine methyl ester (L-NAME; Calbiochem) was perfused at a rate of $4 \mu \mathrm{l} / \mathrm{min}$ to quantify $\mathrm{NO}$-dependent vasodilation at all sites ${ }^{(38,39)}$. After infusion of L-NAME and subsequent stabilisation of a post-L-NAME plateau in skin blood flow, 28 mm-sodium nitroprusside (SNP) (Nitropress; Abbott Laboratories) was perfused and local temperature was increased to $43^{\circ} \mathrm{C}$ to elicit maximal dilation $\left(\mathrm{CVC}_{\max }\right)^{(37,40)}$. Studies in our laboratory and others have demonstrated that this protocol is highly specific to eNOS production of $\mathrm{NO}$ and allows the direct quantification of functional NO-dependent vasodilation in the cutaneous microcirculation $^{(38,41,42)}$.

Cutaneous erythrocyte flux was continually measured directly over each microdialysis site with an integrated laser-Doppler flowmetry probe placed in a local heating unit (Moor Instruments SHO2). Mean arterial pressure (MAP) was measured at the brachial artery throughout the protocol using an automated blood pressure monitor (CardioCap; GE Healthcare). Cutaneous vascular conductance (CVC) was calculated as erythrocyte flux divided by MAP and expressed as a per cent of site-specific maximal vasodilation $\left(\% \mathrm{CVC}_{\max }\right)^{(37,43)}$.

\section{Data acquisition and statistical analysis}

Sample size was determined $a$ prior $i$ by power analysis $(P=0 \cdot 8$, $\alpha=0.05$ ). Data were collected using Windaq (Windaq; DATAQ Instruments) at a frequency of $40 \mathrm{~Hz}$. A three-way (dietary treatment $\times$ local treatment $\times$ subject) repeated-measures, mixed-model ANOVA was used to detect dietary treatment and local treatment differences in local heating plateau, NO-dependent vasodilation and maximal CVC (version 9.1.3; SAS). A two-way (dietary treatment $\times$ subject), repeatedmeasures ANOVA was used to detect dietary treatment differences in plasma $\mathrm{Na}$ and angiotensin II. Bonferroni post boc corrections were performed to account for multiple comparisons when necessary. Significance was accepted at $\alpha=0.05$. All values are presented as means with their standard errors.

\section{Results}

There was no difference in baseline or maximal (28 mm-SNP, $43^{\circ} \mathrm{C}$ ) CVC between microdialysis sites or across treatments.

Fig. 2 shows original data records of the skin blood flow response normalised to maximal $\mathrm{CVC}\left(\% \mathrm{CVC}_{\max }\right)$ during local heating in the control and ascorbate-treated microdialysis sites of one subject following non-dairy dietary $\mathrm{Na}$ (pretzel, $1120 \mathrm{mg} \mathrm{Na}$ ) and dairy cheese $\mathrm{Na}$ (Cheddar cheese, $1120 \mathrm{mg} \mathrm{Na}$ ) intakes. The per cent decrease with nitric oxide synthase inhibition (L-NAME) following each treatment is indicated.

Fig. 3 illustrates the total vasodilatory response to local heating (local heating plateau, $\% \mathrm{CVC}_{\max }$ ) in Ringer's (control) and ascorbate-perfused microdialysis sites following each dietary 

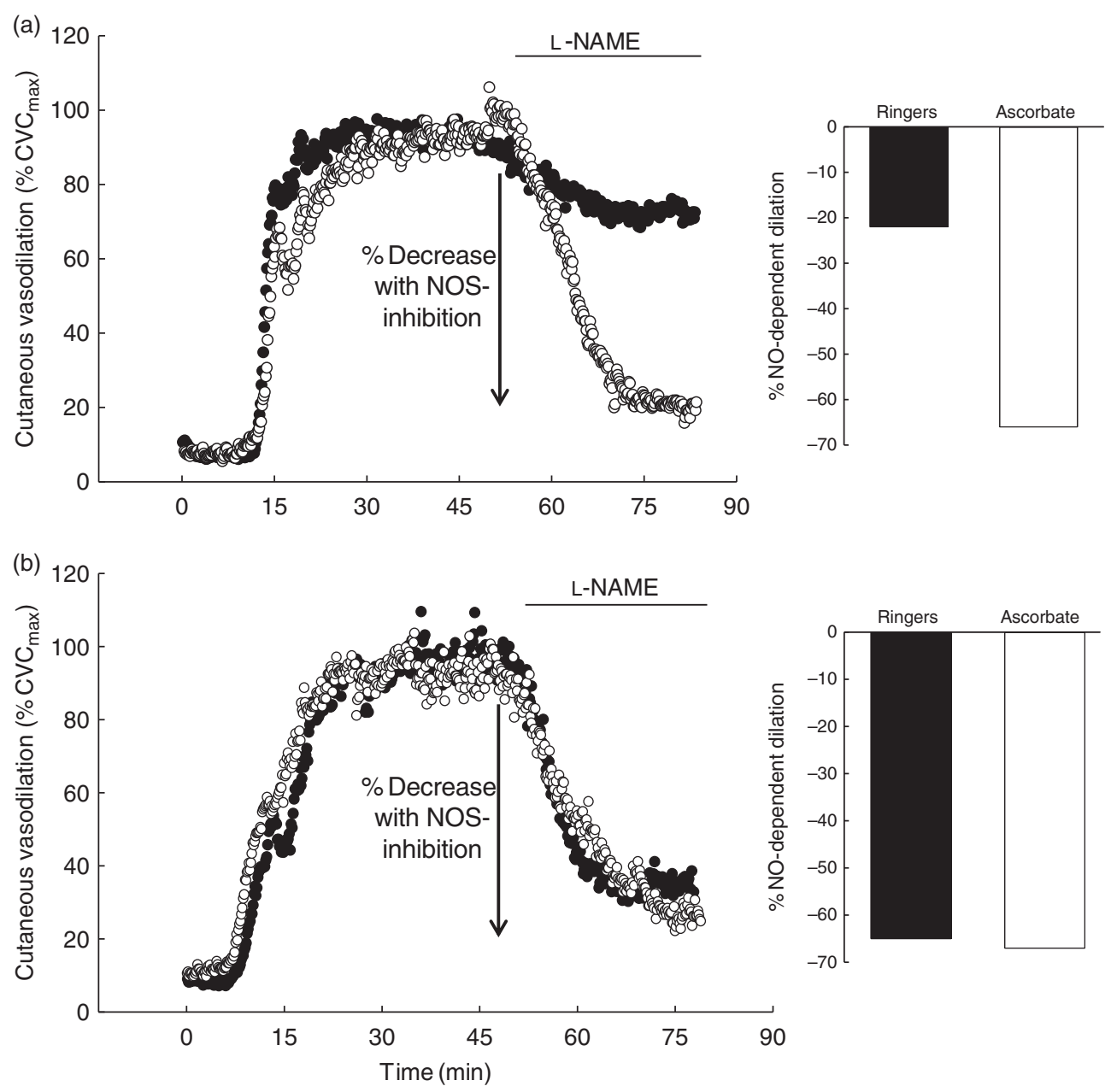

Fig. 2. Representative tracing of skin blood flow $\left(\% \mathrm{CVC}_{\max }\right)$ during local heating in the control and ascorbate-treated microdialysis sites of one subject following nondairy dietary sodium (a; pretzel, $1120 \mathrm{mg} \mathrm{Na}$ ) and dairy cheese sodium ( $\mathrm{b}$; Cheddar cheese, $1120 \mathrm{mg} \mathrm{Na}$ ) consumption. The difference between the local heating plateau and the post- $N^{G}$-nitro-L-arginine methyl ester (L-NAME) plateau indicates the vasodilation attributed to the production of nitric oxide (NO) by endothelial nitric oxide synthase (eNOS) (\%NO-dependent dilation). CVC, cutaneous vascular conductance.

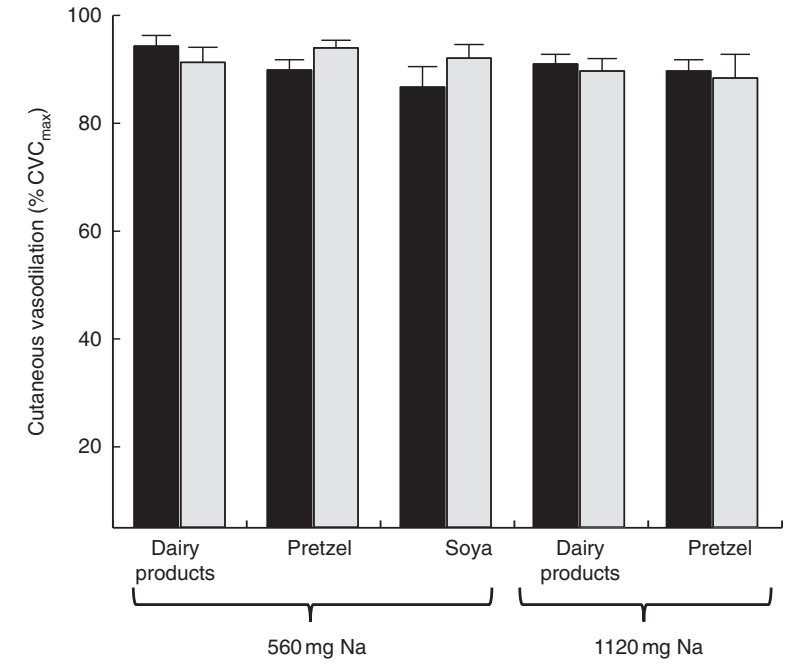

Fig. 3. Values are means $(n$ 14), with their standard errors of vasodilation response $\left(\% \mathrm{CVC}_{\max }\right)$ to local heating in Ringer's solution $(\boldsymbol{\square}$, control) and ascorbate-perfused ( $\square$, antioxidant) microdialysis sites following each dietary treatment. CVC, cutaneous vascular conductance. treatment. There was no difference in the local heating plateau between sites or among dietary treatments (all $P>0 \cdot 05$ ).

Fig. 4 shows the percent NO-dependent vasodilation during local heating in Ringer's (control) and ascorbate-perfused microdialysis sites following each dietary treatment. NOdependent vasodilation was greater following $560 \mathrm{mg} \mathrm{Na}$ contained in dairy cheese (57 (SEM 3) \%) compared with $560 \mathrm{mg}$ $\mathrm{Na}$ in soya cheese ( 42 (sem 3) \%; $P=0.002)$ or $560 \mathrm{mg} \mathrm{Na}$ in pretzels (43 (sEm 4)\%; $P=0 \cdot 004$ ). NO-dependent vasodilation was also greater following $1120 \mathrm{mg} \mathrm{Na}$ contained in dairy cheese (55 (SEM 5)\%) compared with $1120 \mathrm{mg} \mathrm{Na}$ in pretzels (46 (SEM 5) \%; $P=0 \cdot 04$ ). Local ascorbate perfusion augmented NO-dependent vasodilation compared with the control microdialysis site following $\mathrm{Na}$ ingestion from soya cheese (control: 42 (sem 3) $v$. ascorbate: $54(\operatorname{sem} 3) \%)(P=0 \cdot 01)$ and pretzel treatments with $560 \mathrm{mg} \mathrm{Na}$ (control: 43 (SEM 4) $v$. ascorbate: 56 (sem 5) \%; $P=0.006$ ) and $1120 \mathrm{mg} \mathrm{Na}$ (control: 46 (SEM 5) $v$. ascorbate: 56 (sem 3) \%; $P=0 \cdot 02$ ). Local ascorbate perfusion did not augment NO-dependent vasodilation compared with the control microdialysis site following $560 \mathrm{mg} \mathrm{Na}$ ingestion (control: 57 (sem 3) $v$. ascorbate: 60 (sem 3)\%; $P=0.6)$ and 


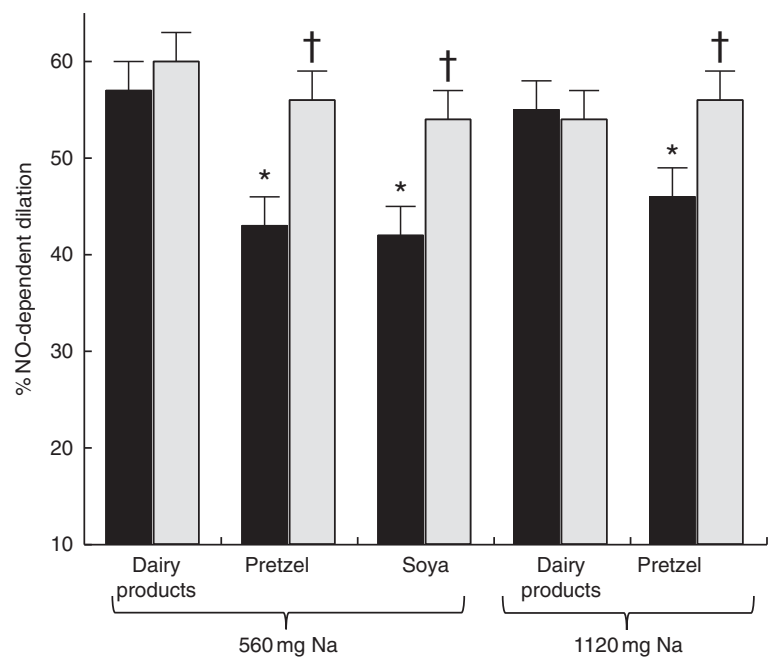

Fig. 4. Values are means ( $n$ 14), with their standard errors of \%NO-dependent vasodilation response to local heating in Ringer's solution ( $\square$, control) and ascorbate-perfused ( $\square$, antioxidant) microdialysis sites following each dietary treatment. ${ }^{*} P<0.05$ compared with dairy products control within sodium ingestion. $\dagger P<0.05$ compared with Ringer's site within dietary treatment. NO, nitric oxide.

$1120 \mathrm{mg} \mathrm{Na}$ ingestion (control: 55 (SEM 5) $v$. ascorbate: 54 (sem 3) \%; $P=0.7$ ) from dairy cheese.

There were no differences in plasma $\mathrm{Na}$ or angiotensin II concentrations at baseline, or 90 min after ingestion, among any of the dietary treatments (Na: $P=0 \cdot 1$ main effect of treatment, $P=0.2$ main effect of time) (angiotensin II: $P=0.6$ main effect of treatment, $P=0.8$ main effect of time).

\section{Discussion}

To our knowledge, this is the first study to directly examine the potential protective effect of Cheddar cheese on dietary $\mathrm{Na}$ induced microvascular endothelial dysfunction. Our data demonstrate that acute (single-meal) dairy cheese consumption is protective against $\mathrm{Na}$-induced impairments in NO-dependent vasodilation in the microcirculation. Further, acute localised administration of the non-specific antioxidant ascorbate normalised NO-dependent vasodilation following non-dairy $\mathrm{Na}$ ingestion, but had no effect on NO-dependent vasodilation after ingesting natural cheese, suggesting that non-Na components of natural cheese protect against acute Na-induced endothelial dysfunction in the microvasculature of healthy, older adults. The primary finding of this study is that the presence of bioactive proteins in dairy product-based natural cheese ameliorates acute Na-induced reductions in NO-dependent vasodilation by reducing ascorbate-sensitive oxidants. These data suggest that paradoxically increasing dietary $\mathrm{Na}$ by increasing cheese consumption may not confer the same CVD risk as dietary $\mathrm{Na}$ consumption in the absence of dairy products.

High dietary $\mathrm{Na}$ consumption is independently associated with elevated arterial blood pressure ${ }^{(15)}$ as well as increased cardiovascular morbidity and mortality ${ }^{(16)}$. Individual $\mathrm{Na}$ excretion resulting from increased dietary intake of $\mathrm{Na}>5.8 \mathrm{~g} / \mathrm{d}$ is strongly associated with increased systolic and diastolic pressures of $10-11$ and $6 \mathrm{mmHg}$, respectively. High-quality meta-analyses indicate that reducing $\mathrm{Na}$ intake reduces blood pressure and the risk of stroke and fatal $\mathrm{CHD}^{(44)}$.

Animal studies of the vascular effects of high dietary $\mathrm{Na}$ implicate endothelium-derived oxidative stress, particularly the production of superoxide, in reduced NO bioavailability and endothelial dysfunction ${ }^{(17-21)}$. Similarly, human studies demonstrate that $\mathrm{Na}$ restriction $(\leq 1.5 \mathrm{~g} / \mathrm{d})$ reverses age-associated endothelial dysfunction by increasing NO-dependent vasodilation and by decreasing superoxide dismutase expression ${ }^{(22)}$. Even short-term increases in dietary $\mathrm{Na}(7 \mathrm{~d})$ induce microvascular dysfunction measured in the cutaneous circulation of healthy young adults ${ }^{(25)}$ - an impairment that is mediated by increases in oxidant stress and occurs independent of changes in blood pressure $^{(31)}$. Similar to our current findings, Dickinson et $a l^{(27)}$ demonstrated that a single high-salt meal significantly suppresses brachial flow-mediated dilation 30 and $60 \mathrm{~min}$ after ingestion in healthy adults. Collectively, the animal and human literature agree that elevated dietary $\mathrm{Na}$ consumption impairs endothelial function and reduces NO bioavailability via increased oxidant stress mechanisms, even in instances where patients do not have overt CVD. Our data add to this body of literature, suggesting that a single high-Na meal/snack from non-dairy sources acutely reduces NO-dependent vasodilation in healthy, older adults.

The positive impact of chronic dairy product consumption on cardiovascular health has been demonstrated in many population-based studies ${ }^{(45,46)}$. Increased total dairy product intake is associated with improvements in global measures of vascular health and function including blood pressure ${ }^{(47)}$, pulse wave velocity ${ }^{(48)}$, arterial compliance ${ }^{(47)}$ and arterial stiffness $^{(46)}$. The precise mechanisms by which dairy products may confer cardiovascular benefits are currently unclear but include angiotensin-converting enzyme inhibition ${ }^{(6-8)}$, protection and enhancement of bioavailable $\mathrm{NO}^{(9-11)}$, and antiinflammatory and antioxidant properties ${ }^{(9,12-14)}$ of dairy proteins. As no single and specific mechanism has been definitively shown to account for the beneficial effects of increased dairy product intake on vascular function, it is likely that lifetime increases in dietary dairy product consumption confer cardiovascular benefits through several of these putative mechanisms. However, given the specific role of oxidant stress in dietary Na-induced vessel dysfunction, we focused our investigation on the antioxidant properties of dairy proteins. In support of this global hypothesis, our data suggest that the antioxidant properties of dairy proteins may play a primary role in the protection against dietary $\mathrm{Na}$-induced reductions in $\mathrm{NO}$ bioavailability. Furthermore, we did not observe changes in circulating angiotensin II in response to our acute dietary treatments.

In the present study, we did not observe a reduction in the total vasodilator response to local heating of the skin, but rather we found attenuation in the direct functional quantification of NO-mediated vasodilation with non-dairy $\mathrm{Na}$ ingestion. These findings agree with earlier studies performed in our laboratory, which suggests that middle-aged adults maintain total vasodilator responsiveness to local heating but have reduced eNOS-mediated vasodilation compared with young adults ${ }^{(33)}$. The current data suggest that a secondary NO-independent pathway is up-regulated to compensate for the decrease in eNOS function following acute $\mathrm{Na}$ consumption. However, 
endothelial-derived NO is synthesised ubiquitously throughout the vasculature and plays a crucial anti-atherogenic vasoprotective role. Given the putative role of $\mathrm{NO}$ in vascular health and vessel function, as well as possible age-associated reductions in other NO-independent endothelial pathways (PG, endothelium-derived hyperpolarising factors, etc. ${ }^{(49,50)}$, interventions that target the production and protection of $\mathrm{NO}$ at the endothelium are clinically relevant strategies to preserve vascular health and reduce CVD risk across the lifespan.

This study examined acute (single meal) vascular responses to dietary $\mathrm{Na}$ with and without dairy products. As expected, we did not observe a time- or treatment-dependent change in plasma $\mathrm{Na}$ concentrations. Plasma $\mathrm{Na}$ concentration is tightly regulated, and our findings are consistent with other dietary studies in which high dietary $\mathrm{Na}$ is associated with vessel dysfunction independent of changes in plasma $\mathrm{Na}$ concentrations ${ }^{(31)}$. We selected our two Na doses on the basis of two and four servings of natural Cheddar cheese. Interestingly, we did not observe a dose-response relationship between dietary $\mathrm{Na}$ from non-dairy sources and attenuated NO-dependent dilation. This may have occurred because our doses were relatively close together or because our doses were high enough that we were at or near a ceiling effect. The dose-response relationship between acute dietary $\mathrm{Na}$ and endothelial dysfunction was not an experimental end point in this study; however, further research in this area is warranted.

Our test foods were specifically matched for dietary $\mathrm{Na}$, with the soya cheese comparison included to account for potential differences with fat content and gastric emptying. There was a difference in protein content between Cheddar cheese and soya cheese meals in this study. As such, we cannot rule out the possibility that protein from non-dairy sources may similarly affect NO-dependent dilation. Furthermore, our study design did not account for differences in fat or carbohydrate composition between treatments - a factor that may influence the inflammatory milieu of the vascular endothelium ${ }^{(51,52)}$. In addition, we did not match our test foods for Ca content. Ca itself may have a beneficial effect on the vascular endothelium and may also enhance renal $\mathrm{Na}$ excretion. However, the literature on the efficacy of $\mathrm{Ca}$ supplementation for improved cardiovascular outcomes is equivocal $^{(53,54)}$. Despite these limitations, given the documented antioxidant properties of dairy peptide hydrolysates ${ }^{(55)}$ and the beneficial effect of dairy peptide ingestion on vascular endothelial function in humans ${ }^{(5,56)}$, our findings fit within the broader hypothesis that specific antioxidant properties of hydrolysed dairy proteins play a role in preserved or maintained vascular function. Collectively, our data strongly suggest that dairy product ingestion protects against acute $\mathrm{Na}$-induced endothelial dysfunction and that this protective effect is mediated by the antioxidant properties of milk proteins. It is still unknown whether this vasoprotection is maintained over longer periods of elevated dietary $\mathrm{Na}$ intake. Furthermore, it is unclear whether this effect is dependent on $\mathrm{Na}$ being directly incorporated in the dairy products (e.g. natural cheese) or whether the same benefits would occur if the diet contained high amounts of dairy products and high Na separately (e.g. pretzels and milk). Further studies of the protective antioxidant mechanisms of dairy proteins as well as their chronic role in vasoprotection against high dietary $\mathrm{Na}$ are warranted.

\section{Summary}

Overall, the present study suggests that the macronutrients in natural cheeses ameliorate Na-induced vessel dysfunction following a high-Na meal through antioxidant mechanisms. Increased dairy product consumption is associated with a decreased risk of cardiovascular morbidity and mortality, and our data suggest that the antioxidant properties of dairy proteins likely contribute to this association by protecting against dietary $\mathrm{Na}$-induced impairments in vascular function. Consequently, increasing dietary dairy product intake may represent a modifiable and non-pharmacological lifestyle factor that can increase vascular health and function through the production and protection of bioavailable NO.

\section{Acknowledgements}

The authors are grateful to the subjects for their time and effort and to Susan Slimak, RN, and Jane Pierzga, MS, for their assistance.

This research was supported by Dairy Management Inc.

A. E. S. designed the study, conducted the study, analysed the data and performed statistical analysis, wrote the paper and had primary responsibility for the final content; B. K. A. conducted the study, analysed the data and wrote the paper; W. L. K. designed the study and wrote the paper; L. M. A. designed the study, analysed the data, wrote the paper and had primary responsibility for the final content. All the authors read and approved the final version of the manuscript. All laboratory analyses were conducted at Pennsylvania State University.

There are no conflicts of interest.

\section{References}

1. Mozaffarian D, Benjamin EJ, Go AS, et al. (2015) Heart disease and stroke statistics - 2015 update: a report from the American Heart Association. Circulation 131, e29-e322.

2. Crichton GE \& Alkerwi A (2014) Dairy food intake is positively associated with cardiovascular health: findings from observation of cardiovascular risk factors in Luxembourg study. Nutr Res 34, 1036-1044.

3. Markey O, Vasilopoulou D, Givens DI, et al. (2014) Dairy and cardiovascular health: friend or foe? Nutr Bull 39, 161-171.

4. Wang L, Manson JE, Buring JE, et al. (2008) Dietary intake of dairy products, calcium, and vitamin $\mathrm{D}$ and the risk of hypertension in middle-aged and older women. Hypertension 51, 1073-1079.

5. Ballard KD \& Bruno RS (2015) Protective role of dairy and its constituents on vascular function independent of blood pressure-lowering activities. Nutr Rev 73, 36-50.

6. Xu JY, Qin LQ, Wang PY, et al. (2008) Effect of milk tripeptides on blood pressure: a meta-analysis of randomized controlled trials. Nutrition 24, 933-940.

7. Murakami M, Tonouchi H, Takahashi R, et al. (2004) Structural analysis of a new anti-hypertensive peptide (beta-lactosin B) isolated from a commercial whey product. J Dairy Sci 87, 1967-1974.

8. van der Zander K, Jakel M, Bianco V, et al. (2008) Fermented lactotripeptides-containing milk lowers daytime blood pressure in high normal-to-mild hypertensive subjects. J Hum Hypertens 22, 804-806. 
9. Xia Z, Liu M, Wu Y, et al. (2006) N-acetylcysteine attenuates TNF-alpha-induced human vascular endothelial cell apoptosis and restores eNOS expression. Eur J Pharmacol 550, 134-142.

10. Szabo C, Hardebo JE \& Salford LG (1992) Role of endothelium in the responses of human intracranial arteries to a slight reduction of extracellular magnesium. Exp Physiol 77, 209-211.

11. Turpeinen AM, Jarvenpaa S, Kautiainen H, et al. (2013) Antihypertensive effects of bioactive tripeptides-a random effects meta-analysis. Ann Med 45, 51-56.

12. Jain SK, Velusamy T, Croad JL, et al. (2009) L-cysteine supplementation lowers blood glucose, glycated hemoglobin, CRP, MCP-1, and oxidative stress and inhibits NF-kappaB activation in the livers of Zucker diabetic rats. Free Radic Biol Med 46, 1633-1638.

13. Tsai GY, Cui JZ, Syed H, et al. (2009) Effect of N-acetylcysteine on the early expression of inflammatory markers in the retina and plasma of diabetic rats. Clin Experiment Ophthalmol 37, $223-231$.

14. De Mattia G, Bravi MC, Laurenti O, et al. (1998) Reduction of oxidative stress by oral $\mathrm{N}$-acetyl-L-cysteine treatment decreases plasma soluble vascular cell adhesion molecule-1 concentrations in non-obese, non-dyslipidaemic, normotensive, patients with non-insulin-dependent diabetes. Diabetologia 41, 1392-1396.

15. Elliott P, Stamler J, Nichols R, et al. (1996) Intersalt revisited: further analyses of 24 hour sodium excretion and blood pressure within and across populations. Intersalt Cooperative Research Group. BMJ 312, 1249-1253.

16. O'Donnell M, Mente A \& Yusuf S (2015) Sodium intake and cardiovascular health. Circ Res 116, 1046-1057.

17. Liu Y, Rusch NJ \& Lombard JH (1999) Loss of endothelium and receptor-mediated dilation in pial arterioles of rats fed a short-term high salt diet. Hypertension 33, 686-688.

18. Lenda DM \& Boegehold MA (2002) Effect of a high salt diet on microvascular antioxidant enzymes. $J$ Vasc Res 39, 41-50.

19. Nurkiewicz TR, Wu G, Li P, et al. (2010) Decreased arteriolar tetrahydrobiopterin is linked to superoxide generation from nitric oxide synthase in mice fed high salt. Microcirculation 17, 147-157.

20. Zhu J, Mori T, Huang T, et al. (2004) Effect of high-salt diet on NO release and superoxide production in rat aorta. $A m J$ Physiol Heart Circ Physiol 286, H575-H583.

21. Zhu J, Huang T \& Lombard JH (2007) Effect of high-salt diet on vascular relaxation and oxidative stress in mesenteric resistance arteries. J Vasc Res $\mathbf{4 4}, 382-390$.

22. Jablonski KL, Racine ML, Geolfos CJ, et al. (2013) Dietary sodium restriction reverses vascular endothelial dysfunction in middle-aged/older adults with moderately elevated systolic blood pressure. J Am Coll Cardiol 61, 335-343.

23. Jablonski KL, Gates PE, Pierce GL, et al. (2009) Low dietary sodium intake is associated with enhanced vascular endothelial function in middle-aged and older adults with elevated systolic blood pressure. Ther Adv Cardiovasc Dis 3, 347-356.

24. Tzemos N, Lim PO, Wong S, et al. (2008) Adverse cardiovascular effects of acute salt loading in young normotensive individuals. Hypertension 51, 1525-1530.

25. DuPont JJ, Greaney JL, Wenner MM, et al. (2013) High dietary sodium intake impairs endothelium-dependent dilation in healthy salt-resistant humans. J Hypertens 31, 530-536.

26. Eisenach JH, Gullixson LR, Kost SL, et al. (2012) Sex differences in salt sensitivity to nitric oxide dependent vasodilation in healthy young adults. J Appl Physiol (1985) 112, 1049-1053.

27. Dickinson KM, Clifton PM \& Keogh JB (2011) Endothelial function is impaired after a high-salt meal in healthy subjects. Am J Clin Nutr 93, 500-505.
28. Holowatz LA, Thompson-Torgerson CS \& Kenney WL (2008) The human cutaneous circulation as a model of generalized microvascular function. J Appl Physiol 105, 370-372.

29. IJzerman RG, de Jongh RT, Beijk MA, et al. (2003) Individuals at increased coronary heart disease risk are characterized by an impaired microvascular function in skin. Eur J Clin Invest 33, 536-542

30. Abularrage CJ, Sidawy AN, Aidinian G, et al. (2005) Evaluation of the microcirculation in vascular disease. J Vasc Surg $\mathbf{4 2}$, $574-581$.

31. Greaney JL, DuPont JJ, Lennon-Edwards SL, et al. (2012) Dietary sodium loading impairs microvascular function independent of blood pressure in humans: role of oxidative stress. J Physiol 590, 5519-5528.

32. DuPont JJ, Farquhar WB \& Edwards DG (2011) Intradermal microdialysis of hypertonic saline attenuates cutaneous vasodilatation in response to local heating. Exp Physiol 96, 674-680.

33. Bruning RS, Santhanam L, Stanhewicz AE, et al. (2012) Endothelial nitric oxide synthase mediates cutaneous vasodilation during local heating and is attenuated in middle-aged human skin. J Appl Physiol 112, 2019-2026.

34. Holowatz LA \& Kenney WL (2007) Local ascorbate administration augments NO- and non-NO-dependent reflex cutaneous vasodilation in hypertensive humans. Am J Physiol Heart Circ Physiol 293, H1090-H1096.

35. Holowatz LA, Thompson CS \& Kenney WL (2006) Acute ascorbate supplementation alone or combined with arginase inhibition augments reflex cutaneous vasodilation in aged human skin. Am J Physiol Heart Circ Physiol 291, H2965-H2970.

36. Boutrou R, Gaudichon C, Dupont D, et al. (2013) Sequential release of milk protein-derived bioactive peptides in the jejunum in healthy humans. Am J Clin Nutr 97, 1314-1323.

37. Minson CT, Berry LT \& Joyner MJ (2001) Nitric oxide and neurally mediated regulation of skin blood flow during local heating. J Appl Physiol (1985) 91, 1619-1626.

38. Alexander LM, Kutz JL \& Kenney WL (2013) Tetrahydrobiopterin increases NO-dependent vasodilation in hypercholesterolemic human skin through eNOS-coupling mechanisms. Am J Physiol Regul Integr Comp Physiol 304, R164-R169.

39. Stanhewicz AE, Greaney JL, Larry Kenney W, et al. (2014) Sex- and limb-specific differences in the nitric oxidedependent cutaneous vasodilation in response to local heating. Am J Physiol Regul Integr Comp Physiol 307, R914-R919.

40. Johnson JM, O'Leary DS, Taylor WF, et al. (1986) Effect of local warming on forearm reactive hyperaemia. Clin Physiol 6, 337-346.

41. Bruning RS, Santhanam L, Stanhewicz AE, et al. (2012) Endothelial nitric oxide synthase mediates cutaneous vasodilation during local heating and is attenuated in middle-aged human skin. J Appl Physiol (1985) 112, 2019-2026.

42. Kellogg DL Jr, Zhao JL \& Wu Y (2009) Roles of nitric oxide synthase isoforms in cutaneous vasodilation induced by local warming of the skin and whole body heat stress in humans. J Appl Physiol (1985) 107, 1438-1444.

43. Minson CT (2010) Thermal provocation to evaluate microvascular reactivity in human skin. J Appl Physiol 109, $1239-1246$

44. Aburto NJ, Ziolkovska A, Hooper L, et al. (2013) Effect of lower sodium intake on health: systematic review and meta-analyses. BMJ 346, f1326.

45. Moore LL, Bradlee ML, Singer MR, et al. (2012) Dietary Approaches to Stop Hypertension (DASH) eating pattern and 
risk of elevated blood pressure in adolescent girls. Br J Nutr 108, 1678-1685.

46. Livingstone KM, Lovegrove JA, Cockcroft JR, et al. (2013) Does dairy food intake predict arterial stiffness and blood pressure in men?: evidence from the Caerphilly Prospective Study. Hypertension 61, 42-47.

47. Yoshizawa M, Maeda S, Miyaki A, et al. (2009) Additive beneficial effects of lactotripeptides and aerobic exercise on arterial compliance in postmenopausal women. Am J Physiol Heart Circ Physiol 297, H1899-H1903.

48. Crichton GE, Elias MF, Dore GA, et al. (2012) Relations between dairy food intake and arterial stiffness: pulse wave velocity and pulse pressure. Hypertension 59, 1044-1051.

49. Holowatz LA, Thompson-Torgerson C \& Kenney WL (2010) Aging and the control of human skin blood flow. Front Biosci (Landmark Ed) 15, 718-739.

50. Minson CT, Holowatz LA, Wong BJ, et al. (2002) Decreased itric oxide- and axon reflex-mediated cutaneous vasodilation with age during local heating. I Appl Physiol (1985) 93, 1644-1649.
51. Botham KM \& Wheeler-Jones CP (2013) Postprandial lipoproteins and the molecular regulation of vascular homeostasis. Prog Lipid Res 52, 446-464.

52. Mah E, Noh SK, Ballard KD, et al. (2011) Postprandial hyperglycemia impairs vascular endothelial function in healthy men by inducing lipid peroxidation and increasing asymmetric dimethylarginine:arginine. J Nutr 141, 1961-1968.

53. Reid IR, Bolland MG, Sambrook PN, et al. (2011) Calcium supplementation: balancing the cardiovascular risks. Maturitas 69, 289-295.

54. Reid IR, Bolland MJ \& Grey A (2010) Does calcium supplementation increase cardiovascular risk? Clin Endocrinol (Oxf) 73, 689-695.

55. Zhang QX, Jin MM, Zhang L, et al. (2015) Hydrophobicity of whey protein hydrolysates enhances the protective effect against oxidative damage on PC 12 cells. J Dairy Res 82, 1-7.

56. Ballard KD, Mah E, Guo Y, et al. (2013) Low-fat milk ingestion prevents postprandial hyperglycemia-mediated impairments in vascular endothelial function in obese individuals with metabolic syndrome. J Nutr 143, 1602-1610. 